\title{
Pregnancy-specific antigens in the sheep: application to the diagnosis of pregnancy
}

\author{
Mildred Cerini, J. K. Findlay and R. A. S. Lawson* \\ Reproduction Research Section, Department of Physiology, University of Melbourne and \\ * Department of Agriculture, Victoria, S.S. Cameron Laboratory, State Research Farm, \\ Werribee 3030, Australia
}

\begin{abstract}
Summary. Antisera to 14-day-old sheep embryos were raised in rabbits and used to detect antigens specific to pregnancy by immunofluorescent staining and haemagglutination. Non-specific antibodies were removed by repeated absorptions of the antisera with homogenates of liver and kidney from non-pregnant ewes. The pregnancy-specific antigens were detected using immunofluorescence in the embryo, myometrium, maternal blood and CL as early as Day 8. No fluorescence was detected in pituitary, hypothalamus, liver, kidney, skeletal muscle or endometrium of pregnant ewes, or in any tissues of non-pregnant ewes. Haemagglutination occurred when a 1:8 dilution of rabbit anti-sheep embryo sera was added to blood obtained from ewes between Days 6 and 50 of pregnancy, but not when added to blood from nonpregnant ewes, rams and wethers or from pregnant mares, sows and cows. The immunological activity was removed from the anti-sheep embryo sera by absorption with homogenates of 14-day-old sheep embryo or pregnant uterus, or erythrocytes from Day 14 pregnant ewes, confirming that the antigens were specific to pregnancy.

The presence of these antigens provides a basis for a haemagglutination test for pregnancy from Day 6 after mating and may be involved in the maternal recognition of pregnancy in the ewe.
\end{abstract}

\section{Introduction}

In many mammals the functional life-span of the $\mathrm{CL}$ is prolonged during pregnancy. In the sheep, for example, an embryo must be present in the uterus on or before Day 12 after mating if the function of the CL is to be prolonged (Moor, 1968). However, the nature of the stimulus causing this prolongation is not known.

Immunological tests for pregnancy in women are based upon the agglutination, by specific antibodies, of sheep erythrocytes or latex particles in the presence of human chorionic gonadotrophin (see Hobson, 1974). Similar immunological tests could be developed for the sheep if antigen(s) specific to early pregnancy could be found. This paper describes experiments to investigate the presence of antigens in sheep which are specific to pregnancy and which might be involved in maintaining the CL.

\section{Materials and Methods}

\section{Tissue preparation}

Embryos were obtained from the uteri of sheep on Day 14 (Moor \& Rowson, 1964) using $0 \cdot 154$ M-sodium chloride as the flushing medium. Morphologically normal embryos were either frozen at $-10^{\circ} \mathrm{C}$ for later use in inoculations, or transferred to $10 \%$ phosphate-buffered formalin for subsequent histological examination.

Samples of uterus, ovary, hypothalamus, pituitary, skeletal muscle, liver and kidney were taken from non-pregnant sheep on Days 8-15 after oestrus (Day 0), and from pregnant sheep on Days 8-17 of pregnancy. Immediately after removal the tissues were fixed in $10 \%$ phosphate-buffered formalin. 


\section{Antiserum production}

Two adult New Zealand rabbits (R4 and R5) were injected intramuscularly with homogenates of whole sheep embryos (14-day-old) emulsified with an equal volume of Freund's complete adjuvant (C.S.L., Melbourne). The inoculation was repeated 4 weeks later. Subsequently, the rabbits received injections of embryo homogenates alone at weekly intervals. They were bled 6 days after each injection. Species-specific and other irrelevant antibodies were removed from the antisera by successive absorptions with homogenates of liver and kidney from non-pregnant sheep.

\section{Immunofluorescent staining}

Sandwich fluorescent staining (Nairn, 1969) was used to localize antigens. Frozen sections $(6 \mu \mathrm{m})$ of the fixed embryos and other ovine tissues were cut at $-20^{\circ} \mathrm{C}$, treated with the antisera for $30 \mathrm{~min}$, and washed in phosphate-buffered saline (PBS; $0.145 \mathrm{M}-\mathrm{NaCl}, 0.01 \mathrm{M}$-phosphate at $\mathrm{pH} \mathrm{7.1)} \mathrm{for} 20 \mathrm{~min}$ with two changes of buffer. The sections were then treated with sheep anti-rabbitglobulin conjugated with fluorescein isothiocyanate (Wellcome Reagents Ltd, England) for $30 \mathrm{~min}$, washed again for $20 \mathrm{~min}$, and subsequently mounted with phosphate-buffered glycerol for fluorescence microscopy. To provide tests for antibody specificity, tissues were treated with: (i) PBS; (ii) normal (preimmune) rabbit serum; (iii) antisera fully neutralized by absorption with whole embryo homogenates; (iv) antisera absorbed with ovine liver and kidney; or (v) antisera to ovine LH, progesterone, or prostaglandin F (PGF). After fluorescence microscopy the sections were stained with haematoxylin and eosin and re-examined.

\section{Haemagglutination}

Heparinized venous blood was collected from animals at various stages of the oestrous cycle, and during pregnancy to Day 50. A 5\% (v/v) suspension of erythrocytes in PBS was prepared and

Table 1. The relative intensity of immunofluorescent staining in tissues of pregnant and non-pregnant ewes treated with anti-sheep embryo sera

\begin{tabular}{|c|c|c|c|c|c|}
\hline \multirow[b]{3}{*}{ Tissues } & \multicolumn{4}{|c|}{ Immune serum } & \multirow{3}{*}{$\begin{array}{c}\begin{array}{c}\text { Pre- } \\
\text { immunization } \\
\text { serum }\end{array} \\
\begin{array}{c}\text { Unabsorbed } \\
\text { or absorbed } \\
\text { with liver }\end{array}\end{array}$} \\
\hline & \multirow[b]{2}{*}{ Unabsorbed } & \multicolumn{3}{|c|}{ Absorbed with: } & \\
\hline & & Liver only & Liver + kidney & Liver+embryo & \\
\hline \multicolumn{6}{|l|}{ Pregnant sheep* } \\
\hline Embryo and membranes & +++ & ++ & $t++$ & - & - \\
\hline Uterus (myometrium) & +++ & +++ & +++ & - & - \\
\hline Corpus luteum & +++ & +++ & ++ & - & - \\
\hline $\begin{array}{l}\text { Skeletal muscle } \\
\text { Pituitary }\end{array}$ & + & + & - & - & - \\
\hline $\begin{array}{l}\text { Hypothalamus } \\
\text { Kidney } \\
\text { Liver }\end{array}$ & + & - & - & - & - \\
\hline \multicolumn{6}{|l|}{ Non-pregnant sheep $\dagger$} \\
\hline Uterus & + & - & - & - & - \\
\hline $\begin{array}{l}\text { Corpus luteum } \\
\text { Skeletal muscle } \\
\text { Pituitary }\end{array}$ & + & - & - & - & $\rightarrow$ \\
\hline $\begin{array}{l}\text { Hypothalamus } \\
\text { Kidney } \\
\text { Liver }\end{array}$ & - & - & - & - & - \\
\hline
\end{tabular}

* Days 8-17 (Day 0 = day of oestrus); 1-3 animals/day; total no. of animals examined $=18$.

$\dagger$ Days 8-15 (Day 0 = day of oestrus); 1-3 animals/day; total no. of animals examined $=11$. 
pipetted dropwise into blood agglutination trays. One drop of a dilution of: (a) unabsorbed antisera; (b) antisera absorbed with homogenates of ovine liver and kidney; (c) antisera absorbed with an homogenate of a Day 14 sheep embryo; or (d) preimmune sera, was added, mixed and allowed to stand for $30 \mathrm{~min}$. The blood was then examined and scored for intensity of agglutination $(+++=$ maximum agglutination).

\section{Results}

\section{Immunofluorescent staining}

The results of immunofluorescent staining of various tissues are shown in Table 1. From Day 8 until Day 17 of pregnancy both the cytoplasm and the cell membranes of the embryonic tissue stained intensely with the unabsorbed anti-embryo sera. This intense fluorescence remained after absorption of the antisera with ovine liver and kidney homogenates. The fluorescence in other tissues treated with unabsorbed antisera was: (a) intense on the endothelial lining of blood vessels and on the cells bordering the tissue spaces in the myometrium of the pregnant uterus, (b) less intense in the cytoplasm of some luteal cells in the $\mathrm{CL}$, and (c) intense on the membranes of erythrocytes present in all of these tissues on Days 8-17 of pregnancy. This fluorescence remained after absorption of the antisera with homogenates of ovine liver and kidney. In sections of pituitary, hypothalamus, kidney, liver and skeletal muscle, only the erythrocytes and very occasionally the endothelial lining of blood vessels showed fluorescence after absorption of the antiserum with ovine liver homogenate.

The staining of embryonic tissues, uteri, CL and erythrocytes from pregnant ewes was inhibited by absorption of the antiserum with an homogenate of a Day 14 embryo, Day 12 pregnant uterus or by absorption with erythrocytes from a Day 14 pregnant sheep. Repeated absorptions with homogenates of liver or kidney, or erythrocytes from non-pregnant sheep did not inhibit the fluorescence.

In non-pregnant sheep, tissues showed a low level of fluorescence with unabsorbed antisera, but after one absorption with ovine liver these tissues did not fluoresce. Preimmune rabbit serum or PBS did not give fluorescence in any tissues. Immunofluorescent staining was not detected in embryos, myometrium, erythrocytes and CL from Day 12 and Day 14 pregnant ewes when antisera

Table 2. The agglutination with anti-sheep embryo sera of erythrocytes from pregnant and non-pregnant ewes, rams and wethers

\begin{tabular}{|c|c|c|c|c|c|c|}
\hline & & \multicolumn{4}{|c|}{ Immune serum } & \multirow{3}{*}{$\begin{array}{c}\begin{array}{c}\text { Pre- } \\
\text { immunization } \\
\text { serum }\end{array} \\
\text { Unabsorbed }\end{array}$} \\
\hline & & \multirow[b]{2}{*}{ Unabsorbed } & \multicolumn{3}{|c|}{ Absorbed with: } & \\
\hline \multicolumn{2}{|c|}{ Origin of erythrocytes } & & Liver only & Liver + kidney & Liver+embryo & \\
\hline \multicolumn{7}{|l|}{ Ewes } \\
\hline $\begin{array}{l}\text { Day of pregnancy* } \\
\quad(n=5)\end{array}$ & $\begin{array}{c}4 \\
6 \\
9 \\
12 \\
16 \\
18 \\
22-50\end{array}$ & $\begin{array}{l}+++ \\
+++ \\
+++ \\
+++ \\
+++ \\
+++ \\
+++\end{array}$ & $\begin{array}{r}++ \\
++ \\
+++ \\
++ \\
++ \\
++ \\
+++\end{array}$ & $\begin{array}{l}- \\
++ \\
++ \\
++ \\
++ \\
++ \\
++\end{array}$ & $\begin{array}{l}- \\
- \\
- \\
- \\
- \\
-\end{array}$ & $\begin{array}{l}- \\
- \\
- \\
- \\
- \\
-\end{array}$ \\
\hline $\begin{array}{l}\text { Days of cycle } \\
(\mathrm{n}=3)\end{array}$ & $4-16$ & +++ & ++ & - & - & - \\
\hline Rams $(n=2)$ & & ++ & ++ & - & - & - \\
\hline Wethers $(n=4)$ & & +++ & ++ & - & - & - \\
\hline
\end{tabular}

Day $0=$ day of oestrus; $n=$ no. of animals tested on each day.

* Pregnancy was confirmed at laparotomy on Days 26 and 50. 
to LH and PGF were used. With antiserum to progesterone, staining was detected in the lutein cells of pregnant ewes, but not in the other tissues examined.

\section{Haemagglutination}

The optimum dilution of the two anti-embryo sera for agglutination tests was found to be $1: 8$ in PBS and this dilution was used for all subsequent agglutination tests (Table 2). Erythrocytes taken from ewes between Days 4 and 50 of pregnancy, from 12 non-pregnant ewes on Days 12 and 14 of the oestrous cycle and from rams and from wethers all showed strong agglutination with the unabsorbed antisera. After absorption of the antisera with ovine liver and kidney homogenates, only erythrocytes from ewes between Days 6 and 50 of pregnancy agglutinated. No agglutination of erythrocytes occurred with preimmune rabbit sera or antisera absorbed with embryonic tissue. Erythrocytes from sows, cows and mares in early pregnancy did not agglutinate with the antiserum either before or after the antiserum had been absorbed with ovine liver and kidney homogenates.

\section{Discussion}

These results demonstrate that, from a very early stage of pregnancy in the ewe, pregnancy-specific antigen(s) occur in the maternal tissues, including the blood. These antigens were also localized in the embryonic tissues. Treatment of the rabbit anti-sheep embryo sera with homogenates of sheep embryo, or uterus or erythrocytes from pregnant and non-pregnant ewes, confirmed that the antigens were specific to pregnancy.

Antigens specific to pregnancy have been described in maternal tissues of a number of animals, e.g. the rat and mouse (Lin et al., 1974), monkey (Behrman et al., 1974) and man (Bohn, 1972). These antigens are mostly found late in pregnancy and some correspond to hormones such as lactogen and gonadotrophin produced by the placenta. Only HCG has been identified early in pregnancy at Days 6-8 after conception (Saxena et al., 1974). Attempts to demonstrate a chorionic gonadotrophin in the sheep have not been successful (Cerini et al., 1973), although a placental lactogen has been found by Day 60 of pregnancy (Kelly et al., 1974).

The origin, identity, and role of the antigens described in this paper are not known, but it is possible to draw several conclusions. They are not one of the hormones associated with the recurrent oestrous cycle, otherwise the antigens should be detected in tissues of non-pregnant animals. Moreover, antisera to LH, progesterone and PGF showed a different pattern of localization in the embryo and maternal tissues from the pregnancy-specific antigens when studied by immunofluorescence.

It is possible that the embryo-specific antigen provides the early signal for the maternal recognition of pregnancy. This embryonic signal is probably anti-luteolytic rather than luteotrophic in action (Denamur et al., 1973), but it is not yet clear whether this factor acts to prevent the secretion, transport or target effect of the uterine luteolysin. Localization of the antigen in the myometrium, blood and CL of the pregnant ewe indicates that all three possible sites of anti-luteolytic action should be investigated.

Whatever the involvement of antigens specific to pregnancy and $\mathrm{CL}$ function, their presence in the maternal circulation can be exploited as the basis of a simple test for pregnancy. The detection of pregnancy by haemagglutination from Day 6 after fertilization is earlier than any other current method of diagnosing pregnancy in farm animals other than surgical intervention. Field trials are now in progress to fully validate and evaluate the test.

We wish to thank Dr Peter Robinson and Miss Roslyn Perry of the Department of Anatomy, University of Melbourne, for providing advice and facilities for the fluorescent antibody technique, and Mr Kerton, Mr Parr and Mr Strickland for help with the animals. The financial assistance of the Australian Wool Research Trust Fund is gratefully acknowledged.

Some techniques described in this paper are subject to patent application, 


\section{References}

Behrman, S.J., Yoshida, T., Amano, Y. \& Paine, P. (1974) Rhesus and squirrel monkey placental specific antigen(s). Am. J. Obstet. Gynec. 118, 616-622.

BoHN, H. (1972) Characterization of the pregnancy associated glycoproteins as acute phase reactants. Their detection in sera from patients with tumours and other diseases. Arch. Gynäk. 213, 54-72.

Cerini, M.E.D., Beck, C., Chamley, W.A., Cumming, I.A., Findlay, J.K. \& Goding, J.R. (1973) The effect of ovine $\mathrm{LH}$ and a placental protein on the maintenance of the corpus luteum in the ewe. $J$. Reprod. Fert. 32, 324.

Denamur, R., Kann, G. \& Short, R.V. (1973) How does the corpus luteum of the sheep know that there is an embryo in the uterus? In The Endocrinology of Pregnancy and Parturition, pp. 2-4. Ed. C. G. Pierrepoint. Alpha Omega Alpha, Cardiff.

HoBson, B.M. (1974) Advances in human pregnancy testing. Biblphy Reprod. 24.
Kelly, P.A., Robertson, H.A. \& Friesen, H.G. (1974) Temporal pattern of placental lactogen and progesterone secretion in sheep. Nature, Lond. 248, 435-437.

Lin, T.M., Halbert, S.P. \& Kieffer, D. (1974) Pregnancy associated serum antigens in the rat and mouse. Proc. Soc. exp. Biol. Med. 145, 62-66.

NaIRN, R.C. (1969) Fluorescent Protein Tracing, 3rd edn. Livingstone, London.

Moor, R.M. (1968) Effect of embryo on corpus luteum function. J. Anim. Sci. 27, Suppl. 1, 97118.

Moor, R.M. \& Rowson, L.E.A. (1964) Influence of the embryo and uterus on luteal function in the sheep. Nature, Lond. 201, 522-523.

Saxena, B.B., Hasan, S.H., HaOur, F. \& SchmidtGollwITZER, M. (1974) Radioreceptor assay of human chorionic gonadotropin: detection of early pregnancy. Science, N.Y. 184, 793-795.

Received 4 March 1975 